\title{
Investigation of short-term effective radiative forcing of fire aerosols over North America using nudged hindcast ensembles
}

\author{
Y. Liu et al. \\ Correspondence to: Yun Qian (yun.qian@pnnl.gov) and Xiu-Qun Yang (xqyang@nju.edu.cn)
}

The copyright of individual parts of the supplement might differ from the CC BY 3.0 License. 


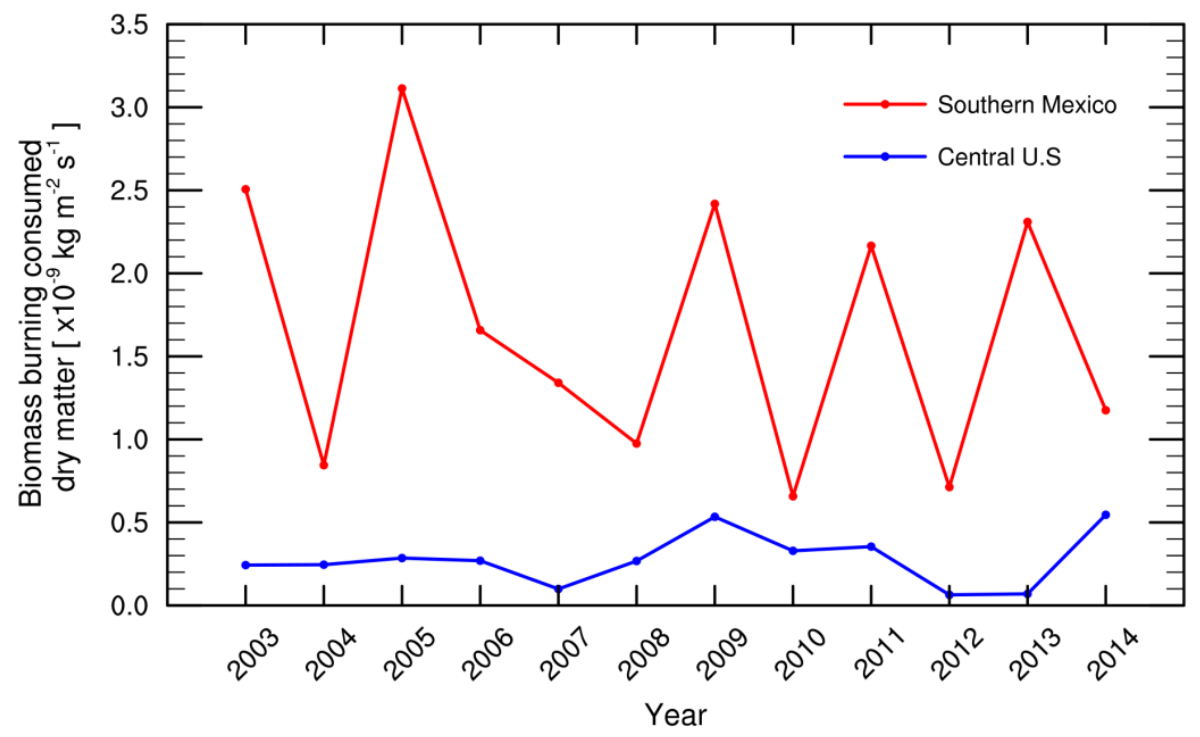

Fig.S1. Time series of regional mean biomass burning consumed dry matter during April in central U.S (blue) and Mexico (red) from GFED v4.1.

Table S1 Regional mean emissions of fire aerosols in April, 2009 from three emission inventories (Unit: $\mathrm{x}^{-12} \mathrm{~kg} \mathrm{~m}^{-2} \mathrm{~s}^{-1}$ ). Numbers in the parentheses show results averaged in April 1-10.

\begin{tabular}{lllllll}
\hline & \multicolumn{2}{c}{ BC } & \multicolumn{2}{c}{ OC } & \multicolumn{2}{c}{ SO2 } \\
\hline & Central & Southern & Central & Southern & Central & Southern \\
& U.S. & Mexico & U.S. & Mexico & U.S. & Mexico \\
\hline GFED v3.1 & $0.25(0.38)$ & $0.69(0.82)$ & $1.82(3.58)$ & $5.60(6.77)$ & $1.35(2.01)$ & $3.69(4.35)$ \\
GFED v4.1s & $0.23(0.34)$ & $1.17(1.44)$ & $1.75(3.24)$ & $8.80(10.76)$ & $1.21(1.81)$ & $6.25(7.69)$ \\
QFED v2.4 & $2.63(3.29)$ & $3.87(3.87)$ & $23.54(32.25)$ & $36.81(36.58)$ & $14.04(17.59)$ & $20.62(20.65)$ \\
\hline
\end{tabular}


Table S2 Regional mean total AOD, fire AOD (difference in total AOD between simulations with and without fire) and the contributions of fire AOD (fire AOD divided by total AOD in the S_NF simulation)during April, 2009 in group A simulations.

\begin{tabular}{lcccccc}
\hline & \multicolumn{3}{c}{ Central U.S. } & \multicolumn{3}{c}{ Southern Mexico } \\
\hline & Total AOD & Fire AOD & Percentage & Total AOD & Fire AOD & Percentage \\
\hline S_NF & 0.066 & & & 0.130 & & \\
S_GF3 & 0.068 & 0.002 & $3.42 \%$ & 0.141 & 0.011 & $8.10 \%$ \\
S_GF4 & 0.070 & 0.004 & $5.63 \%$ & 0.145 & 0.015 & $11.20 \%$ \\
S_QF & 0.099 & 0.033 & $49.33 \%$ & 0.194 & 0.064 & $48.84 \%$ \\
\hline
\end{tabular}

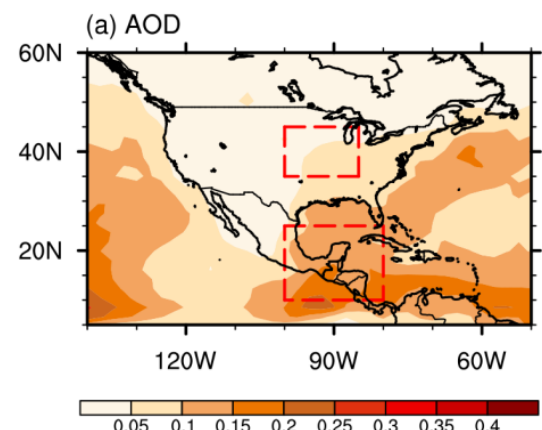

(b) Total Aerosol Forcing

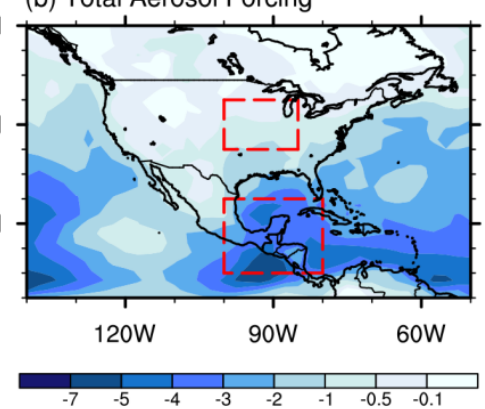

(c) Shortwave Cloud Forcing

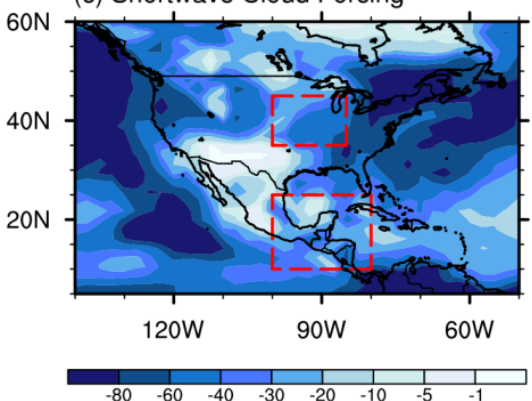

Fig.S2. Spatial distributions of 10-day average (Apr. 1-10) ensemble mean a) AOD, b) total aerosol forcing and c) total shortwave cloud forcing $\left(\mathrm{W} \mathrm{m}^{-2}\right)$ in the simulation without fire emissions (E_NF). 

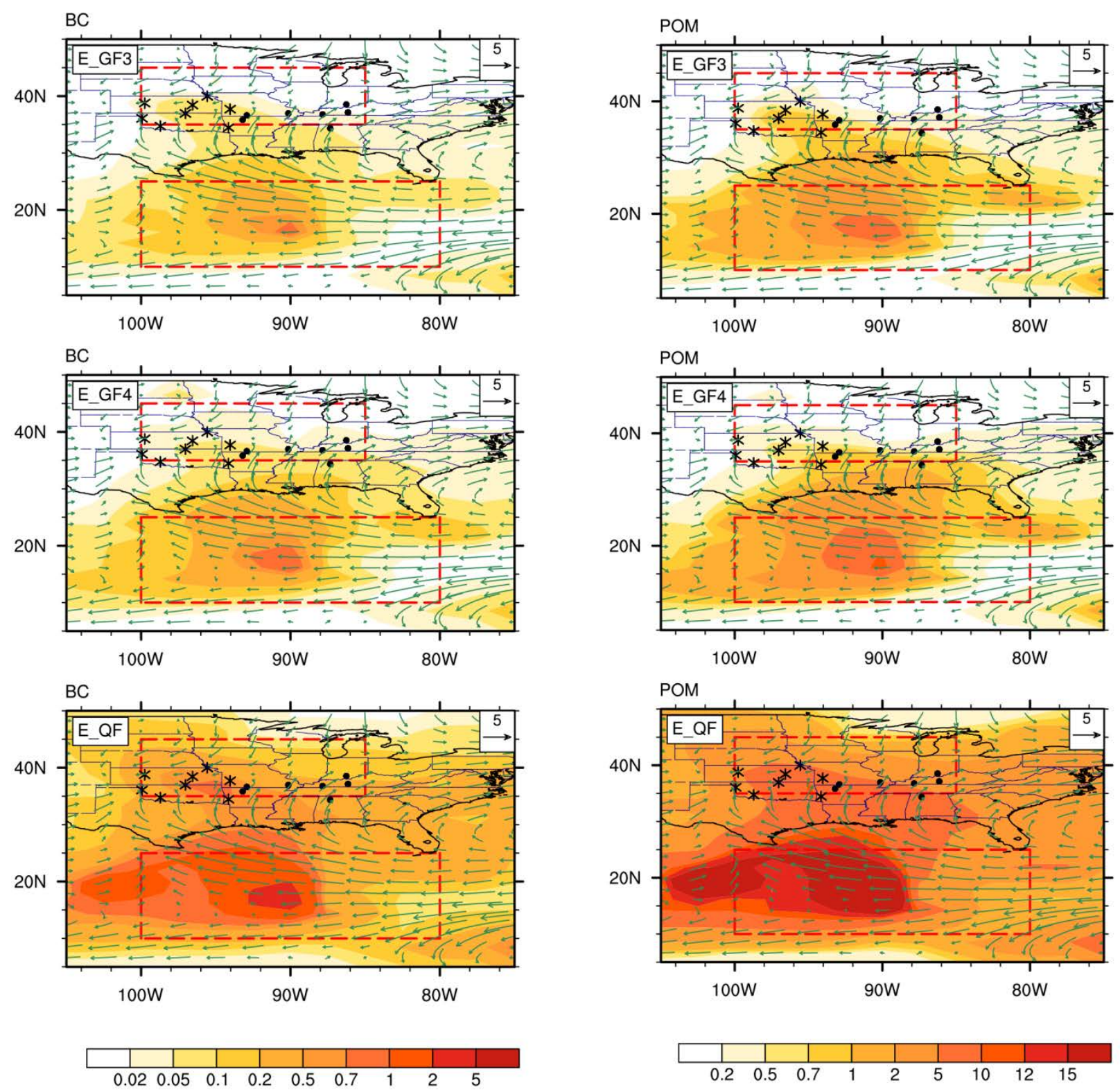

Fig.S3. Spatial distributions of April mean fire BC and fire POM burden (shaded) on IMPROVE observation days in group B simulations (E_GF3/E_GF4/E_QF - E_NF). Vectors denote horizontal winds near $850 \mathrm{hPa}$ in group B fire simulations (E_GF3/E_GF4/E_NF). IMPROVE data sites are marked with asterisks for sites near the source region and with dots for sites in the downwind region. 

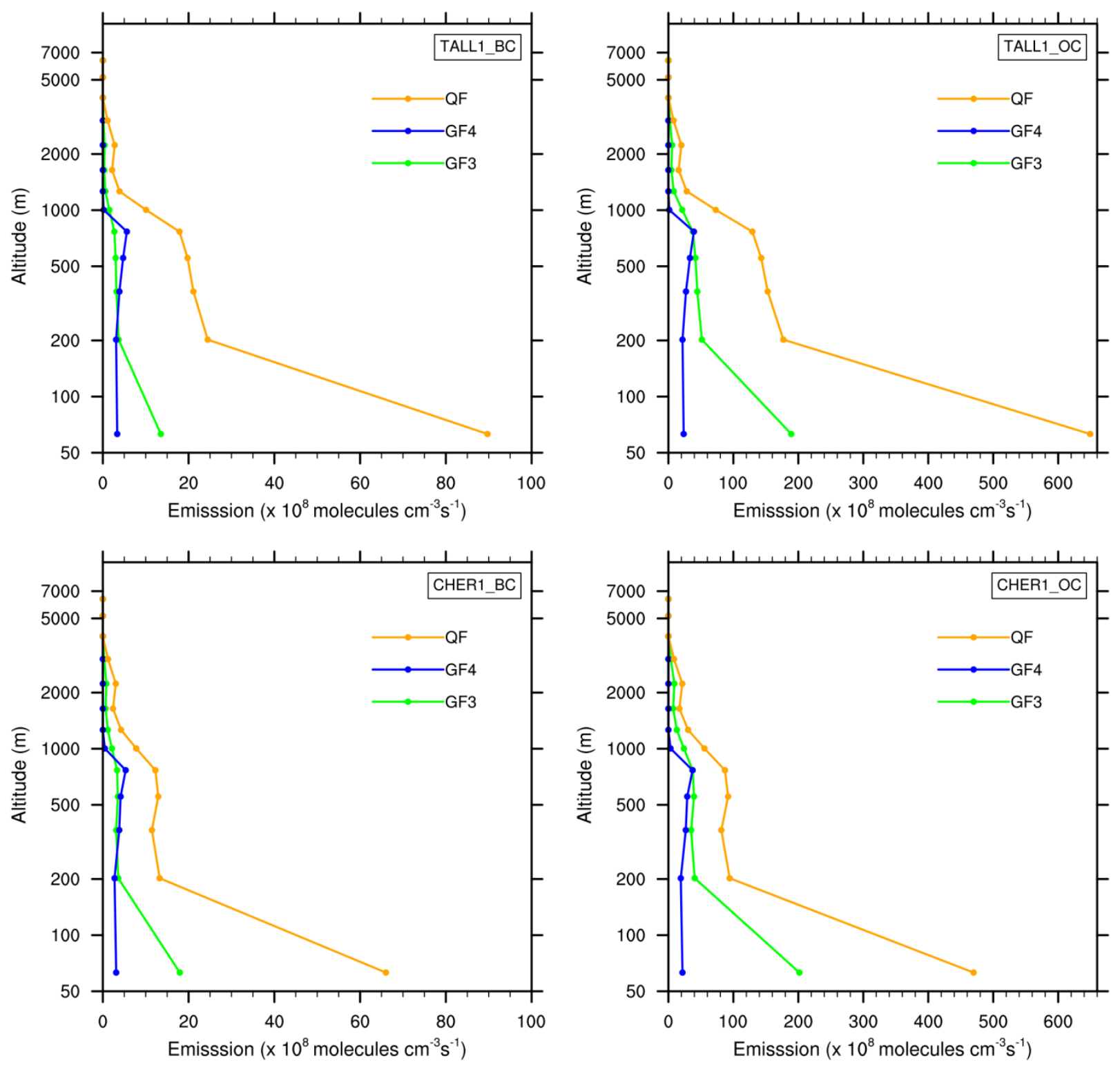

Fig.S4. Vertical profiles of fire emissions of BC and OC used in simulations at sites TALL1 $\left(38.43^{\circ} \mathrm{N}, 96.56^{\circ} \mathrm{W}\right)$ and CHER1 $\left(38.77^{\circ} \mathrm{N}, 99.76^{\circ} \mathrm{W}\right)$. 
Table S3 Regional mean total AOD, fire AOD (differences in AOD between simulations with and without fire) and radiative effects of fire aerosols during April 1-10, 2009 in group B simulations (Unit: $\mathrm{W} \mathrm{m}^{-2}$ ). Total fire aerosol radiative effect is decomposed into shortwave direct radiative effect (SDRE), shortwave cloud radiative effect (SCRE), longwave cloud radiative effect (LCRE) and surface albedo effect (SAE).

\begin{tabular}{lllllll}
\hline & $\begin{array}{c}\text { Total } \\
\text { AOD }\end{array}$ & Fire AOD & SDRE & SCRE & LCRE & Total SAE \\
\hline Central U.S. & & & & & & \\
\hline E_NF & 0.047 & & & & & \\
E_GF3 & 0.050 & 0.003 & 0.02 & -0.86 & 0.04 & 0.02 \\
E_GF4 & 0.050 & 0.003 & -0.01 & -0.39 & 0.002 & -0.003 \\
E_QF & 0.08 & 0.033 & -0.10 & -0.56 & -0.76 & 0.12 \\
\hline Southern Mexico & & & & & & \\
\hline E_NF & 0.135 & & & & & \\
E_GF3 & 0.149 & 0.014 & -0.18 & -1.91 & -0.21 & 0.06 \\
E_GF4 & 0.153 & 0.018 & -0.20 & -2.06 & -0.23 & 0.11 \\
E_QF & 0.202 & 0.067 & -0.86 & -3.02 & -0.47 & 0.14 \\
\hline
\end{tabular}


(a) CDNC

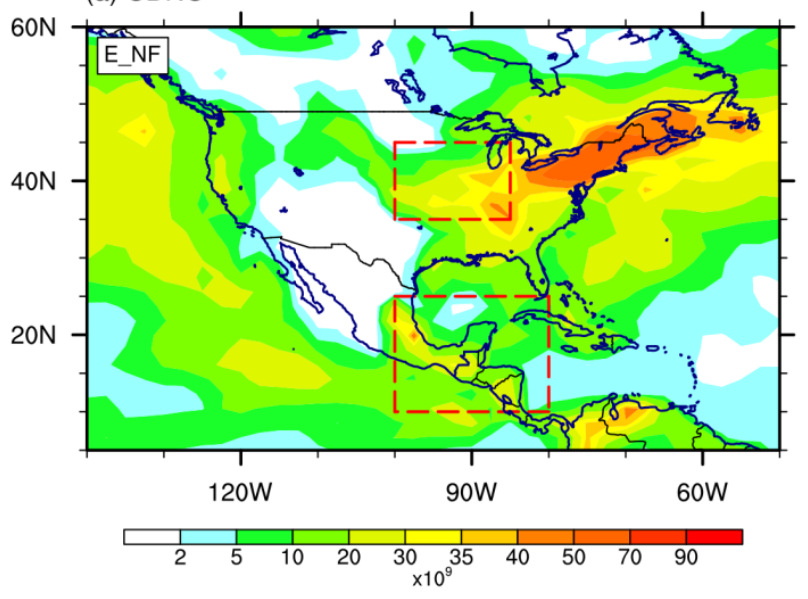

(b) CLDLIQ

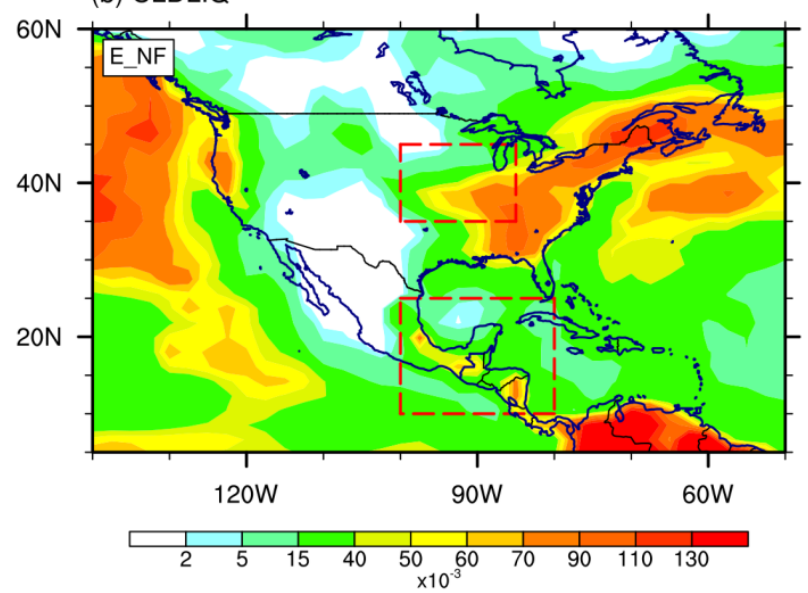

Fig.S5. Spatial distributions of 10-day average (Apr. 1-10) ensemble mean a) column-integrated droplet number concentrations $\left(\mathrm{m}^{-2}\right)$ and b) liquid water path $\left(\mathrm{g} \mathrm{m}^{-2}\right)$ in the E_NF simulations.

(a) (E_QF-E_NF)/E_NF
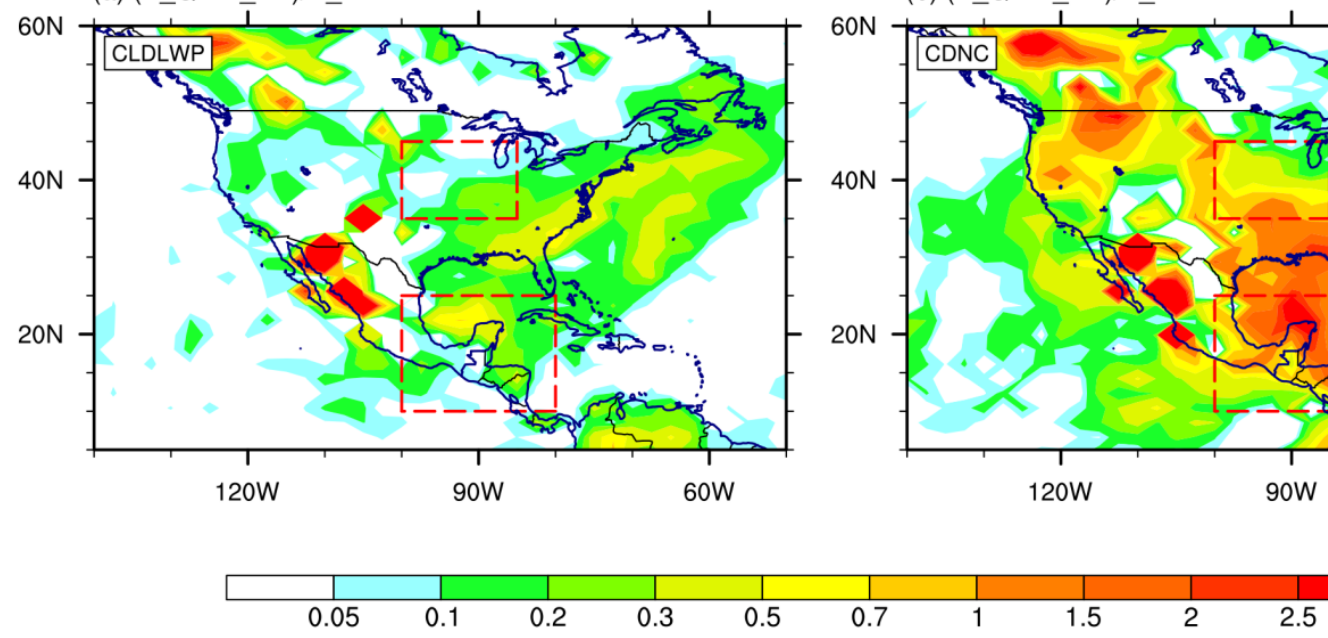

(b) (E_QF-E_NF)/E_NF

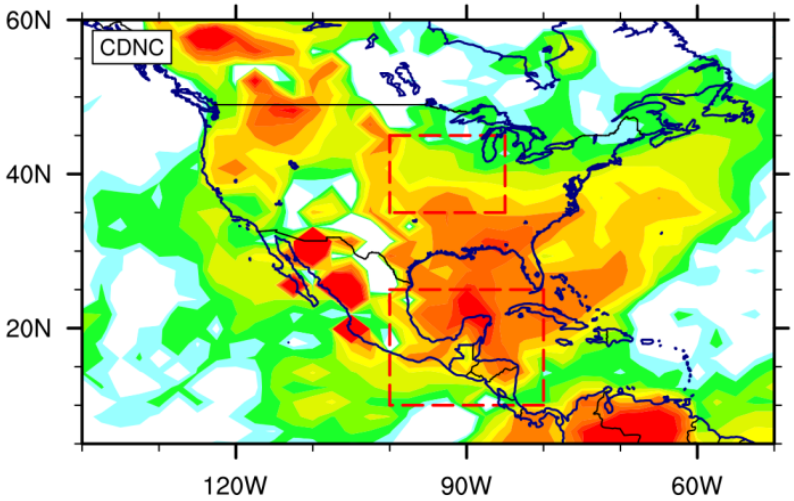

Fig.S6. Relative changes of 10-day average ensemble mean cloud properties between the E_NF and E_QF simulations. a) cloud liquid water path, b) column-integrated droplet number concentration 

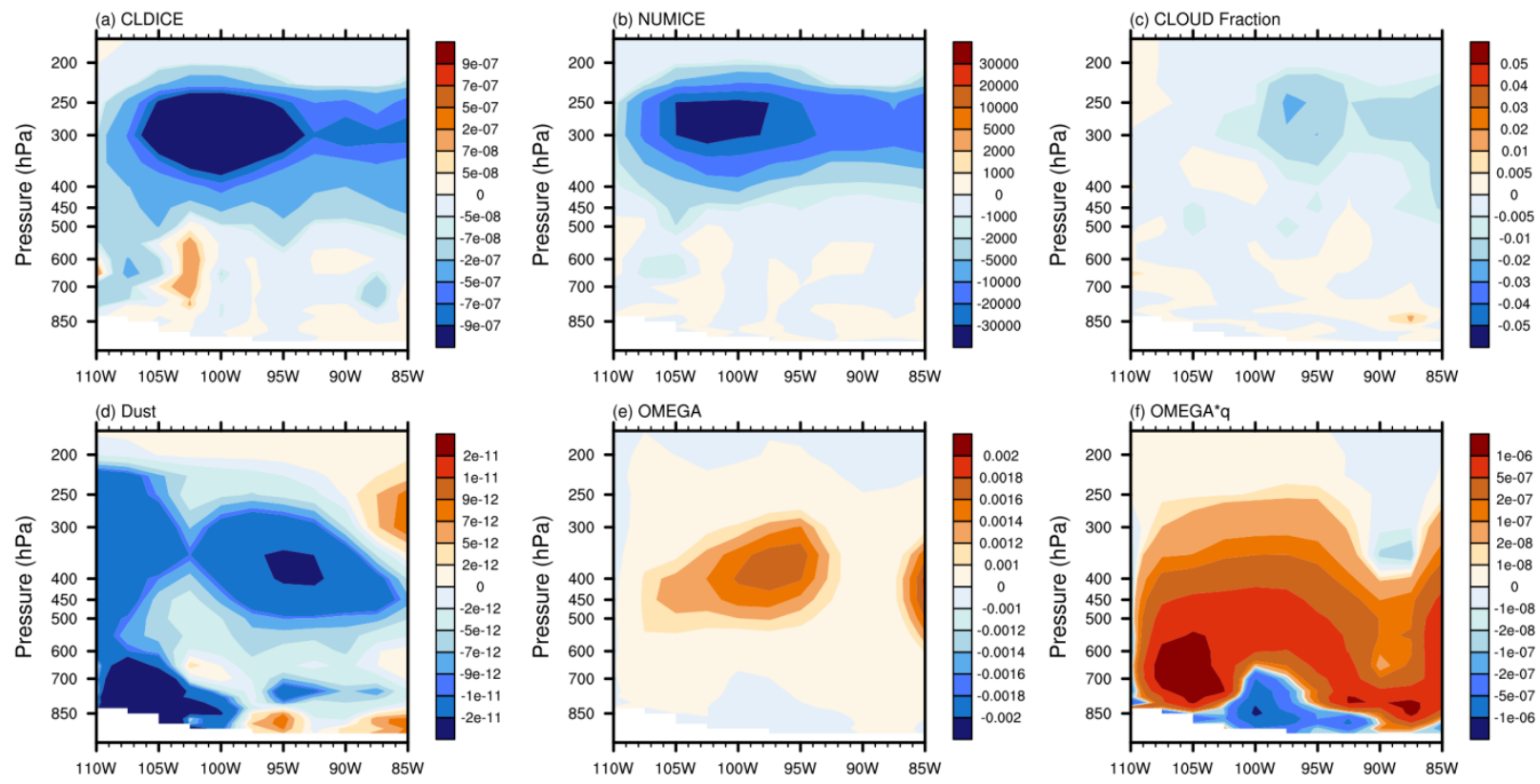

Fig.S7. Pressure and longitude distribution of meridional mean $\left(40-45^{\circ} \mathrm{N}\right)$ difference of 10-day average (April 1 -10) ensemble mean between simulation E_NF and E_QF: a) cloud ice amount $\left(\mathrm{kg} \cdot \mathrm{kg}^{-1}\right) \mathrm{b}$ ) cloud ice number concentration $\left(\mathrm{kg}^{-1}\right) \mathrm{c}$ ) cloud fraction (1) d) Coarse mode dust concentration $\left(\mathrm{kg} \cdot \mathrm{kg}^{-1}\right)$ e) vertical velocity $\left.\left(\mathrm{Pa} \cdot \mathrm{s}^{-1}\right) \mathrm{f}\right)$ vertical moisture transport $\left(\mathrm{kg} \cdot \mathrm{kg}^{-1}\right.$. $\left.\mathrm{Pa} \cdot \mathrm{s}^{-1}\right)$ 
(a) SDRE
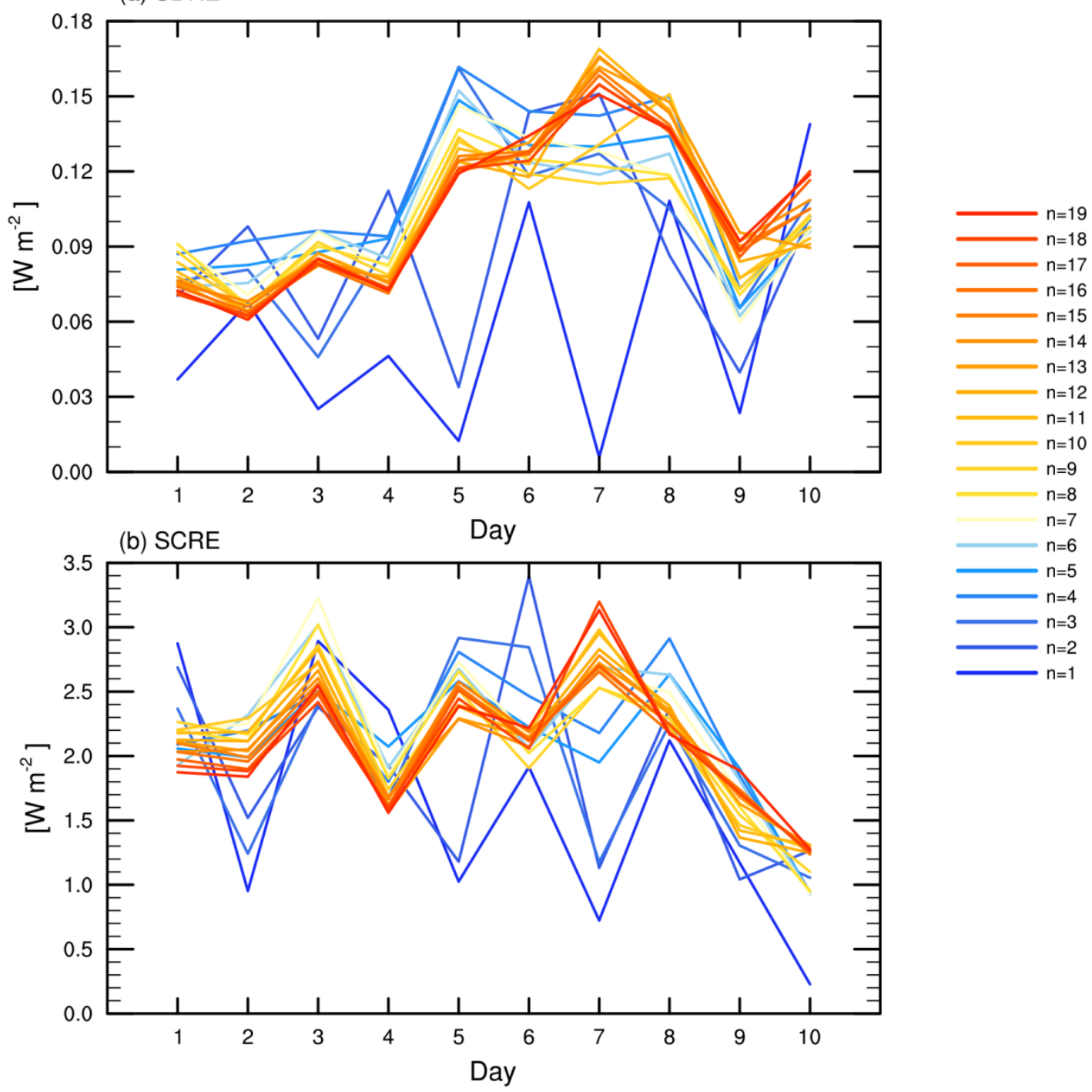

Fig.S8. Time series of ensemble spread of daily regional mean fire aerosol a) SDRE and b) SCRE in Southern Mexico during Apr. 1-10, 2009 in QFED forced ensemble simulations with varying the total number of ensemble member $(n=1-20)$. 